9 Chaussy C, Schmeidt E. Extracorporeal shock wave lithotripsy (ESWL) for kidney stones. An alternative to surgery? Urol Radiol 1984;6:80-7.

10 Eisenberger F, Fuchs G, Miller K, Bub P, Rassweiler J. Extracorporeal shock wave lithotripsy (ESWL) and endourology; an ideal combination for the treatment of kidney stones. World Journal of Urology 1985;3:41-7.

11 Wickham JEA, Webb DR, Payne SR, Kellett MJ, Watkinson G, Whitfield HN. Extracorporeal shock wave lithotripsy: the first 50 patients treated in Britain. Br Med $\mathcal{F}$ 1985;290:1188-9. Alken P, Hardeman S, Wilbert D, Thuroff J, Jacobi GH. Extracorporeal shock wave lithotripsy (ESWL): alternatives and adjuvant procedures. World foumal of Urology 1985:3:48-52.

13 Le Duc A, Cariou G, Cortesse A, Teillac P. La chirurgie rénale percutanée. Atalyse de cent cas de néphrolithotomies percutanees. Annales de Urologie 1984;18:381-5.

14 Gross PF, Goldstein G. Extracorporeal shock wave lithotripsy: a preliminary analysis of its likely economic impact in Australia. Emerging Technology 1985;1:200-15.

15 Grage TB, Zelen $M$. The controlled randomised clinical trial in the evaluation of cancer treatment-the dilemma and alternative trial designs. In: Flamant R, Fohanno C, eds. Evaluation of methods of treatment and diagnostic procedures in cancer. Geneva: International Union Against Cancer, 1982

16 Block JB, Elashoff RM. The randomised clinical trial in evaluation of new cancer treatment. In De Vita VT, Harris B, eds. Methods in cancer research. Vol 18. New York: Academic Press, 1979:259-75

17 Hellman S. Randomised clinical trials and the doctor patient relationship. Cancer Clin Trials 1979;2:189.

8 Relman AS. The new medical-industrial complex. N Engl f Med 1980;303:963-70.

19 Silverman WA. Retrolental fibroplasia: a modem parable. London: Academic Press, 1980.

20 Stocking B. Morrison SL. The image and the reality. Oxford: Oxford University Press for the Nuffield Provincial Hospitals Trust, 1978.

Accepted 20 Januan 1986

\title{
Comparison of treatment of renal calculi by open surgery, percutaneous nephrolithotomy, and extracorporeal shockwave lithotripsy
}

\author{
C R CHARIG, D R WEBB, S R PAYNE, J E A WICKHAM
}

\begin{abstract}
This study was designed to compare different methods of treating renal calculi in order to establish which was the most cost effective and successful. Of 1052 patients with renal calculi, 350 underwent open surgery, 350 percutaneous nephrolithotomy, 328 extracorporeal shockwave lithotripsy (ESWL), and 24 both percutaneous nephrolithotomy and ESWL. Treatment was defined as successful if stones were eliminated or reduced to less than $2 \mathrm{~mm}$ after three months. Success was achieved in $273(78 \%)$ patients after open surgery, $289(83 \%)$ after percutaneous nephrolithotomy, $301(92 \%)$ after ESWL, and $15(62 \%)$ after percutaneous nephrolithotomy and ESWL. Comparative total costs to the NHS were estimated as $£ 3500$ for open surgery, $£ 1861$ for percutaneous nephrolithotomy, $£ 1789$ for ESWL, and $\$ 3210$ for both ESWL and nephrolithotomy. ESWL caused no blood loss and little morbidity and is the cheapest and quickest way of returning patients to normal life.
\end{abstract}

\section{Introduction}

Throughout the 1970 s research and skill improved the success rates of open renal surgery for the large staghorn and smaller renal calculi and allowed all stones to be removed with minimal loss of function. The morbidity associated with such procedures was also reduced. In 1980 percutaneous nephrolithotomy was introduced, whereby a radiologically guided track was made through the skin into the renal collecting system, permitting the stones to be extracted under direct vision with an endoscope. ${ }^{\text {Th }}$ This technique reduces mortality and morbidity and entails a short stay in hospital at low cost to the National Health Service. ${ }^{2}$

In November 1984 the first extracorporeal shockwave lithotripter in the United Kingdom was installed by the St Martin's group of hospitals at the London Stone Centre. This apparatus enables

Institute of Urology and the St Peter's group of hospitals

CR CHARIG, MA, FRCSED, senior house officer, St Paul's Hospital, London WC2

D R WEBB, FRACS, honorary senior registrar (also urologist, London Lithotripter Centre, London W1)

S R PAYNE, MB, FRCS, fellow in percutaneous renal surgery

J E A WICKHAM, MS, FRCS, director of academic unit (also director, London Lithotripter Centre)

Correspondence to: $\mathrm{Mr}$ Charig. kidney stones to be broken up in situ by using focused shock waves generated by an ultrashort, high tension underwater electrical discharge; it obviates the need for invasive surgery, although an anaesthetic is still required. ${ }^{3}$ In all, 750 treatments have now been performed at the London Stone Centre and over 80000 have been performed world wide (Dornier Systems, West Germany).

With any new and capitally expensive treatment three questions need to be answered: What is the difference in mortality? What is the difference in morbidity? Which mode of treatment is the most cost effective? We tried to define the current place of extracorporeal shockwave lithotripsy (ESWL) in the management of renal calculi by comparing 350 cases of open stone removal, 350 cases of percutaneous nephrolithotomy, and 352 cases of ESWL. All patients were treated by the same team of surgeons under the direct supervision of one consultant. Patients in all groups were unselected and treated consecutively over 14 years (open surgery from 1972 to 1980, percutaneous nephrolithotomy from 1980 to 1985, and ESWL in 1985).

\section{Methods}

Open surgery-All renal and ureteric calculi were treated by nephrolithotomy, pyelolithotomy, ureterolithotomy, or a combination of these procedures. Many patients had complicated conditions and had been operated on previously. Some complex renal calculi were removed with the aid of regional hypothermia,${ }^{4}$ in some cases intravenous inosine was used to protect function during controlled ischaemia, and in some cases minimal ischaemia or no clamping of the renal pedicle was used. Intraoperative radiography was commonly used, antibiotics were given routinely, and all patients required general anaesthesia.

Percutaneous nephrolithotomy-The techniques of one and two stage nephrolithotomy used have been extensively described. ${ }^{5}$ This study comprised 150 two stage and 200 one stage nephrolithotomies. All types of stone were treated. In the one stage procedure the tracks were kept patent with an Amplatz sheath and the stones were removed whole or broken up with electrohydraulic lithotripsy or ultrasound ${ }^{67}$ All patients were given prophylactic antibiotics and general anaesthesia.

$E S W L$ - The technique of ESWL used was based on the German experience of the Dornier lithotripter. ${ }^{8}$ The number of shocks was limited to that required to render the stones into particles that could be passed spontaneously (roughly $2 \mathrm{~mm}$ in diameter) ${ }^{7}$ (G W Drach et al, tapes presented at meeting of American Urological Association, 1984). Patients underwent either general or epidural anaesthesia, and all received prophylactic antibiotics. All patients were screened for clotting defects and renal impairment, and urine samples were cultured. Follow up consisted of a plain abdominal $x$ ray examination on the second postoperative day; renal ultrasonography, if clinically indicated by fever or pain; and a plain abdominal $x$ ray examination on the 10th postoperative day and at three 
months. In 25 patients with larger staghorn calculi the portion of the stone in the renal pelvis was removed percutaneously and then ESWL was applied to the residual stone fragments; these patients were considered separately. When patients required unplanned percutaneous nephrolithotomy after ESWL this was recorded as a complication of treatment. In some cases of percutaneous nephrolithotomy and ESWL stones in the upper ureter were manipulated back into the renal pelvis before being treated in the kidney.'

Analysis-In all groups stones were sent for analysis, and all patients underwent metabolic stone screening ${ }^{3}$ For the purpose of this study all details of patients were assessed three months after treatment. The procedures were defined as successful if patients were free of stones at three months or, in the case of ESWL, if stones had been fragmented into particles of less than $2 \mathrm{~mm}$. For each type of treatment the patients were considered in two groups: group 1 were those with stones of a mean diameter of less than 2 $\mathrm{cm}$ and group 2 those with stones of a mean diameter of $2 \mathrm{~cm}$ or more or with multiple stones.

TABLE I-Details of patients in each treatment group

\begin{tabular}{lcccccc}
\hline & \multicolumn{3}{c}{ No (\%) of patients with stones } & & & \\
\cline { 2 - 4 } & $\begin{array}{c}<2 \mathrm{~cm} \\
\text { (group 1) }\end{array}$ & $\begin{array}{c}\geqslant 2 \mathrm{~cm} \\
\text { (group 2) }\end{array}$ & Total & $\begin{array}{c}\text { Mean age } \\
\text { (range) }\end{array}$ & M:F (\%) \\
\hline Nephrolithotomy/pyelolithotomy & $13(6)$ & $218(94)$ & 231 & $45(12-78)$ & $45: 55$ \\
Pyelolithotomy & $31(41)$ & $45(59)$ & 76 & $47(16-72)$ & $51: 49$ \\
Ureterolithotomy & $43(100)$ & & 43 & $46(20-68)$ & $69: 31$ \\
Percutaneous nephrolithotomy & $270(77)$ & $80(23)$ & 350 & $52(23-72)$ & $68: 32$ \\
ESWL & $204(62)$ & $124(38)$ & $328\}$ & $48(22-83)$ & $70: 30$ \\
Percutaneous nephrolithotomy and ESWL & & $24(100)$ & $24\}$ & & \\
\hline
\end{tabular}

TABLE II-Success rate of treatment $t^{\star}$ (figures are numbers (\%) of patients)

\begin{tabular}{|c|c|c|c|}
\hline & Group 1 & Group 2 & Overall \\
\hline $\begin{array}{l}\text { Nephrolithotomy/pyelolithotomy } \\
\text { Pyelolithotomy } \\
\text { Ureterolithotomy }\end{array}$ & $\begin{array}{l}12(92) \\
26(84) \\
43(100)\end{array}$ & $\begin{array}{r}154(71) \\
38(84)\end{array}$ & $\begin{array}{r}166(72) \\
64(84) \\
43(100)\end{array}$ \\
\hline All open procedures & $81 \quad(93)$ & $192(73)$ & $273 \quad(78)$ \\
\hline $\begin{array}{l}\text { Percutaneous nephrolithotomyt } \\
\text { ESWL } \\
\text { Percutaneous nephrolithotomy and } \\
\text { ESWL }\end{array}$ & $\begin{array}{ll}234 & (87) \\
200 & (98)\end{array}$ & $\begin{array}{r}55(69) \\
101(82) \\
15(62)\end{array}$ & $\begin{array}{ll}289 & (83) \\
301 & (92) \\
15 & (62)\end{array}$ \\
\hline
\end{tabular}

* Success defined as no stones at three months or stone reduced to particles $<2 \mathrm{~mm}$ in

†52 with electrohydraulic lithotripsy, 69 with ultrasound.

\section{Results}

Table I shows the subgroups of patients by age, sex, operation, and size of stones. The mean age was between 45 and 52 (range 12-83), and two thirds of patients were male. Most open procedures were for stones greater than $2 \mathrm{~cm}$ in diameter, whereas most of the closed procedures were performed for smaller stones.

Table II compares the success rate by size of stones and shows that overall ESWL had the best success rate of $90 \%(98 \%$ in group 1 and $82 \%$ in group 2$)$.

The proportions of patients who had complications (excluding infective urine) were: after nephrolithotomy/pyelolithotomy 105 patients $(46 \%)(3$ $(23 \%)$ in group $1 ; 102(47 \%)$ in group 2$)$; after pyelolithotomy $27(36 \%)(12$ $(38 \%) ; 15(33 \%))$; after ureterolithotomy $4(9 \%)(0 ; 4(9 \%))$; after percutaneous nephrolithotomy $59(17 \%)(35(13 \%) ; 24(30 \%))$; and after ESWL and percutaneous nephrolithotomy $37(11 \%)(7(3 \%) ; 30(20 \%))$.

Morbidity - Table III lists the complications that occurred after each type

TABLE III-Complications after each procedure (figures are numbers of patients)

\begin{tabular}{|c|c|c|c|c|c|c|c|c|c|c|}
\hline & \multicolumn{2}{|c|}{ Nephrolithotomy } & \multicolumn{2}{|c|}{ Pyelolithotomy } & \multicolumn{2}{|c|}{ Ureterolithotomy } & \multicolumn{2}{|c|}{$\begin{array}{l}\text { Percutaneous } \\
\text { nephrolithotomy }\end{array}$} & \multicolumn{2}{|c|}{ ESWL } \\
\hline & Group 1 & Group 2 & Group 1 & Group 2 & Group 1 & Group 2 & Group 1 & Group 2 & Group 1 & Group 2 \\
\hline Cardiac & & 10 & & & & & 4 & 4 & 6 & $5^{\star}$ \\
\hline Pulmonary & 1 & 32 & 4 & 6 & 1 & & & & & 1 \\
\hline Gastrointestinal & 1 & 3 & & & & & & & & \\
\hline Renal failure & & 9 & 1 & 1 & 1 & & & & & 1 \\
\hline Septicaemia & & 8 & 2 & 1 & & & 20 & 14 & & 5 \\
\hline Obstruction of upper tract & & 5 & 1 & & & & 6 & 6 & & $15+$ \\
\hline Leak & 1 & 16 & 2 & 2 & 2 & & 5 & & & \\
\hline Wound infection & & 19 & 2 & 5 & & & & & $1 \neq$ & 3 \\
\hline More than one complication & 2 & 36 & 2 & 3 & 1 & & 2 & 2 & & \\
\hline
\end{tabular}

^Transient arrythmias

†Treated by needle nephrostomy, percutaneous nephrolithotomy, or ureteroscopy.

†Includes electrive percutaneous nephrolithotomy and ESWL.

Cardiac complications included cardiac arrest, pulmonary embolus and deep venous thrombosis, and cardiac arrhythmias. Pulmonary complications were usually chest infections yielding positive results on sputum culture. Ileus and stress ulcers were the gastrointestinal complications. Renal failure occurred in patients with solitary kidneys; chronic renal failure before treatment was excluded. Septicaemia included transient bacteraemia after operation. Obstruction of the upper tract included obstruction of the pelviureteric junction and ureteric obstruction by calculi but excluded the ureteric calculi that did not obstruct, as is sometimes seen after ESWL (the "Steinstrasse"). Leaks were recorded if urine leaked for more than two days after removal of a drain or nephrostomy tube. Wound infection included abdominal bruising, which sometimes occurs after ESWL.

TABLE IV-Comparative total cost of each part of procedure to NHS

\begin{tabular}{|c|c|c|c|c|c|c|}
\hline & \multicolumn{2}{|c|}{ Inpatient days } & \multicolumn{2}{|c|}{ Outpatient visit } & \multirow{2}{*}{$\begin{array}{c}\text { Cost of } \\
\text { procedure }\end{array}$} & \multirow{2}{*}{$\begin{array}{c}\text { Total cost } \\
\text { (range) } \\
(£)\end{array}$} \\
\hline & No & $\operatorname{Cost}(\boldsymbol{E})^{\star}$ & No & $\operatorname{Cost}(\mathfrak{£}) \dagger$ & & \\
\hline $\begin{array}{l}\text { Nephrolithotomy } \\
\text { Pyelolithotomy }\end{array}$ & $\begin{array}{l}17 \cdot 08 \\
15 \cdot 15\end{array}$ & $\begin{array}{l}2972 \\
2636\end{array}$ & $\begin{array}{l}2 \cdot 4 \\
2 \cdot 4\end{array}$ & $\left.\begin{array}{l}243 \\
243\end{array}\right\}$ & $469 \cdot 28$ & $3500(3324-3660)$ \\
\hline \multicolumn{7}{|l|}{ Percutaneous nephrolithotomy: } \\
\hline $\begin{array}{l}\text { First } \\
\text { Second }\end{array}$ & $\begin{array}{l}5 \cdot 63 \\
8 \cdot 3\end{array}$ & $\begin{array}{r}955 \\
1453\end{array}$ & $\begin{array}{l}2 \cdot 5 \\
2 \cdot 5\end{array}$ & $\left.\begin{array}{l}251 \\
251\end{array}\right\}$ & $407 \cdot 84$ & $1861(1613-2111)$ \\
\hline ESWL & 3.7 & 643 & 3 & 251 & $800 \cdot 00$ & $1739(1689-1789)$ \\
\hline ESWL and percutaneous nephrolithotomy & $9 \cdot 92$ & 1726 & 3 & $276 \cdot 44$ & $1207 \cdot 00$ & 3210 \\
\hline
\end{tabular}

«NHS bed $£ 174$

†First outpatient visit £165, follow up £55·72. 
of treatment. No distinction was made between primary and secondary haemorrhage, and only the total amount of blood required was recorded. During open surgery four patients in group 1 required more than three units of blood, one of whom required 10 units; and 90 patients in group 2 required more than three units of blood, 18 of whom required more than six units and one of whom subsequently underwent nephrectomy. During percutaneous nephrolithotomy no patients in group 1 needed more than three units but two in group 2 did, one of whom required 16 units. No patients who underwent ESWL required blood. Average blood loss was $2 \cdot 6$ units during open surgery and nil during both ESWL and percutaneous nephrolithotomy.

Mortality-Mortality with all three modes of treatment was extremely low: three patients $(0.9 \%)$ died after open surgery, two $(0.7 \%)$ after percutaneous nephrolithotomy, and none after ESWL.

Cost of procedures-A calculation of the overall cost to the NHS (table IV, appendix) showed that ESWL can be the cheapest form of treatment for both large and small stones. The cost to the NHS for sessions on the lithotripter at the stone centre can be further reduced if patients are housed in their referring hospital. The costs do not include the cost of transport to and from the stone centre.

\section{Discussion}

The surgical management of patients with renal calculi has now moved away from operative intervention, but the types of stone do not change. The incidence of stone disease encountered in a major health region is around 1200 cases a year, of which $300-400$ will need surgical intervention (this may increase with ESWL by $10-15 \%(M$ Blacklock, personal communication)). The economic consequences of this are enormous as most patients are around 45 years old and two thirds are male. ${ }^{10}$ ESWL and percutaneous nephrolithotomy, which reduce inpatient stay by $75 \%$, allow patients to return to work far more quickly than open surgery, and with ESWL most patients can resume normal activity within 24 hours of treatment and can return to work in less than a week. ${ }^{3}$

Over 80000 patients have been treated with ESWL world wide and only two have died. Morbidity with this procedure is minimal, as evidenced by the small amount of analgesia required postoperatively. ${ }^{11}$ Complications that arise can be anticipated and treated by a skilled team. Moreover, stones can be cleared in patients who have previously been considered to be unfit for open surgery or technically unsuitable for percutaneous nephrolithotomy. The overall cost of ESWL compares favourably with that of percutaneous nephrolithotomy, and the procedure is far more cost effective than open surgery. ${ }^{12}$ Time spent on treatment by the consultant ( 57 minutes as opposed to 84 minutes for percutaneous nephrolithotomy and 130 minutes for open surgery) and exposure to $x$ rays are considerably less for ESWL, and hence many more patients can be treated. Treatment of one patient an hour is easily realisable.

In overall economic and therapeutic terms, therefore, ESWL is superior to other forms of treatment for most types of stone except cystine and complete staghorn stones. Given the overall incidence of stones in the United Kingdom of $1 \cdot 2-4 \cdot 6 / 10^{4}$, probably five lithotripters are needed in the United Kingdom. The machines are expensive and, to be used efficiently, should form part of an overall stone service and be grouped in units where all forms of endourological skill are available (American Urological Association ad hoc committee, May 1985). More surgeons need to be trained in percutaneous renal surgery so that they can use their skill in conjunction with ESWL, thus allowing more urologists to participate in a complete stone service.

Previously the aim of treatment has been to eliminate all stones as residual calculus results in a high rate of recurrence requiring treatment. ${ }^{14}$ With ESWL gravel may persist in dependent calices with no clinical effect ( $24 \%$ seen on $x$ ray films at three months). It is too early to predict the ultimate fate of these finely fragmented particles as follow up is still less than five years world wide, but because ESWL is so safe further treatment may be undertaken to treat reformed or residual calculi. As yet there is no proved maximum number of treatments that patients may safely undergo, and hence it should be possible to render a patient free of stones and keep him such with repeated ESWL if required.

Our study shows that the size of the stone is a crucial factor in determining the outcome of treatment. Stones greater than $2 \mathrm{~cm}$ in diameter lead to a high failure rate with all forms of treatment, but much less so with ESWL. The prevalence of complications is also increased to up to $46 \%$ in this group, and blood loss is always greater. As confidence with ESWL and percutaneous nephrolithotomy increases larger stones are attempted, accounting for the slight increase in morbidity and failure rates as numbers expand. The complete staghorn is still a major challenge, but with a combination of percutaneous nephrolithotomy and ESWL, using repeated treatments, open surgery may be avoided for nearly all stones.

We thank Sisters V Capper, T Raybold, and L Pinker for their help in compiling the cost figures; Larry Watkinson for the use of the institute's computer services; Ian Carswell in the financial department of the Middlesex Hospital; and the London Stone Centre for making its records freely available. We especially thank Professor N Blacklock for access to his lithotripter pilot study for Greater Manchester.

\section{Appendix}

COMPARATIVE COSTS OF TREATMENT

Open surgery

Theatre time (average $2 \mathrm{~h} 10 \mathrm{~min}$ ) at $£ 87 / \mathrm{h}$ (medical cost $£ 36 / \mathrm{h}$, nursing/portering $£ 26 / \mathrm{h}$, maintenance $£ 25 / \mathrm{h}$ )

Radiology units (120)

Disposables

Special equipment $(£ 10$ per case)

Capital outlay

Hypothermic equipment RHU101 Ortholav

Drugs (inosine at $£ 36 \cdot 23$ for $£ 20$; $£ 20$ per case)

Blood (average $2 \cdot 6$ units at $£ 40 /$ unit)

$$
\begin{array}{rrr} 
& £ 188 \cdot 50 \\
& 68 \cdot 76 \\
& 78 \cdot 02 \\
& 10 \cdot 00 \\
859 & £ 3074 & \\
2215 & & \\
& & 20 \cdot 00 \\
& 104 \cdot 00 \\
\cline { 2 - 2 } \text { Cost per case } & £ 469 \cdot 28
\end{array}
$$

\section{Percutaneous nephrolithotomy}

$X$ ray department time (average $1 \mathrm{~h} 24 \mathrm{~min}$ ) at $£ 74 \cdot 28 / \mathrm{h}$ (medical cost $£ 50 \cdot 15 / \mathrm{h}$, nursing/portering $£ 24 \cdot 13 / \mathrm{h}$ )

Radiology units (180)

Disposables

Special equipment ( $£ 36$ per case) Capital outlay

Wickham operating scope

Rigid stone forceps $\times 2$

Storz optical triradiate and $0^{\circ}$ scope

Wolf electrohydraulic lithotripter

Lithotripter probes $\times 6$

Wolf ultrasonic operator

Wolf sonotrode

Wolf suction pump

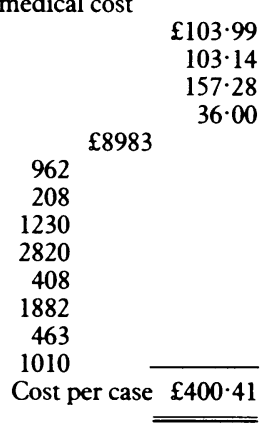

$E S W L^{14}$

Building to house machine

Dornier lithotripter

Ward conversion

$X$ ray guidance for endourology

(£214 000-328 000)

1100000

243000

150000

$1 \cdot 707 \mathrm{~m}-1 \cdot 821 \mathrm{~m}$

Revenue costs ( $£ 1000-1250 /$ year for 5 years)

Medical staff

$£ 81000$

Nursing and ancillary

67547

Maintenance of building and equipment

$10 \%$ depreciation on building

$10 \%$ depreciation on machine

Medical disposables

21400

110000

7300

Rates

Electricity

Electrode (1.7/patient at $£ 200$ each, assuming 1000 patients)

Servicing 
COMPARATIVE COSTS OF ESWL AT PRIVATE AND NHS HOSPITALS

Private hospital

Lithotripsy

Hospital room (£185/day) for 3 days

Anaesthetist

Pathology

Cost to NHS

Lithotripsy ( $£ 3500 /$ session with 4.5 patients treated each session) $\dagger$

Single patient treatment including price

Room for 3 days

$£ 1500$

555

200

351

$£ 2606$

470

$£ 2198$

†Referring hospital would be expected to provide transport and anaesthetist if patient not staying.

\section{References}

1 Payne SR, Ford TF, Wickham JEA. Endoscopic management of upper urinary tract stones. $\mathrm{Br} \mathcal{F}$ Surg 1985;72:822-4
2 Wickham JEA, Kellett MJ, Miller RA. Elective percutaneous nephrolithotomy in 50 patients f Urol 1983;129:904-5

3 Wickham JEA, Webb DR, Payne SR, Kellett MJ, Watkinson G, Whitfield HN. Extracorporeal shockwave lithotripsy: the first 50 patients treated in Britain. Br Med f 1985;290:1188-9.

Wickham JEA, Coe N, Ward JP. One hundred cases of nephrolithotomy under hypothermia. I Urol 1974;112:702-5.

5 Wickham JEA. Percutaneous nephrolithotomy and lithotresis. In: Wickham JEA, Miller RA, eds. Percutaneous renal surgery. Edinburgh: Churchill Livingstone, 1983:108-47.

6 Savage J. Management of renal stones by ultrasonic shattering. Radiography 1984;50:92-5.

7 Clayman R. Techniques in percutaneous removal of renal calculi. $\mathcal{f}$ Urol 1984;23:11-9.

8 Chaussy C, Schmeidt E. Shockwave treatment for stones in the upper urinary tract. Urol Clin North Am 1983;10:743-50.

9 Webb DR, McNicholas T, Whitfield HN, Wickham JEA. Extracorporeal shockwave lithotripsy. Endourology and open surgery. The management and follow-up of 200 patients with urinary calculi. Ann R Coll Surg Engl 1985;67:337-40.

10 Shuster J, Schaeffer RL. Economic impact of kidney stones in white male adults. Urology 1984;4:327-31.

11 Gardiner RA, Norton-Morgan TC, Whitfield HN, Hendry WF, Wickham JEA. Modified lumbotomy versus the oblique loin incision for renal surgery. $B r \mathcal{F}$ Urol 1979;52:256-9.

12 Wickham JEA, Kellett MJ, Miller RA. Percutaneous nephrolithotomy. Results and cost effectiveness. Br f Urol 1983;suppl: 103-6.

13 Miller RA, Fuchs G, Rassweiler J, Eisenberger R. Financial analysis, personal planning and organisational requirements of installation of a kidney lithotripter in a urological department. Eur Urol 1984;10:217-21.

14 Slight W, Wickham JEA. Long term follow up of 100 cases of renal calculi. Br $\mathcal{F}$ Urol 1977;49: $601-4$

(Accepted 20 February 1986)

W0

\section{CLINICAL CURIOS}

\section{Strongyloides stercoralis infection in a former soldier of the Burma campaign: 40 years later}

The nematode worm Strongyloides stercoralis causes infections that may persist for many years because of autoinfection (larvas penetrate perianal skin and pass via tissues to the gut, where they later reproduce). Infections may be asymptomatic or cause diarrhoea, malabsorption, or a pathognomic rash known as larva currens. This is a rapidly moving, linear, eruptional wheal caused by migrating larvas, which is intensely itchy and affects central areas of the body.

A notable proportion of people who were prisoners of the Japanese during the second world war still have strongyloides infection, and it is common among those who worked on the Thai to Burma railway. British soldiers in the Burma campaign often fought in similar jungle environments to the prisoners of war and contracted the infection through touching soil contaminated with faeces.

A 64 year old man had fought in the jungle during the Burma campaign in 1944-5. In 1984 he attended a reunion at which we drew attention to strongyloidiasis. He immediately recognised the creeping, erupting rash as being identical with his own, which occurred about monthly and affected his body and thighs; it had previously been attributed to nerves. Investigations were performed in 1985 . He did not have appreciable blood eosinophilia, but microscopy of stools showed scanty larvas of $S$ stercoralis. He was given mebendazole $200 \mathrm{mg}$ twice daily for two weeks, and his rash cleared.

This man undoubtedly acquired strongyloidiasis in the Far East during the war, and it persisted until treatment 40 years later. The prevalence of strongyloidiasis among prisoners of war who worked on the Thai to Burma railway and were examined 30-40 years later has been variously quoted as $21-37 \%$. As there are about 30000 men in Britain today who fought in the Burma campaign so the total number with strongyloidiasis is probably considerable.

Advice on suspected strongyloidiasis is available from the Department of Tropical Medicine, Liverpool School of Tropical Medicine, Pembroke Place, Liverpool L3 5QA (tel 051708 9393). - G v GILL, Arrowe Park Hospital, Merseyside L49 5PE; D R BELL, School of Tropical Medicine, Liverpool L3 5QA; R J PEARCE, Ipswich IP1 3LU.

\section{Appearance of facial cosmetics as a sign of cerebellar dysfunction}

A 26 year old woman presented with difficulty in walking of four years' duration that had deteriorated more rapidly after the birth of each of her three children. Her brother was confined to a wheelchair. In an attempt to appear presentable she had applied facial cosmetics, producing a sadly bizarre appearance that offered an immediate clue to the underlying diagnosis. Her face was smeared with lipstick, and her eyeshadow had a hopelessly cubist asymmetry. Further examination confirmed the suspicion of cerebellar disease: pale optic discs, absent reflexes, hypotonia, and extensor plantars were found, but no skeletal abnormalities, strongly suggesting Friedreich's ataxia. ${ }^{1}$ Electromyography confirmed the clinical suspicion, showing sensory neuropathy and disturbed function of the posterior quadrant.

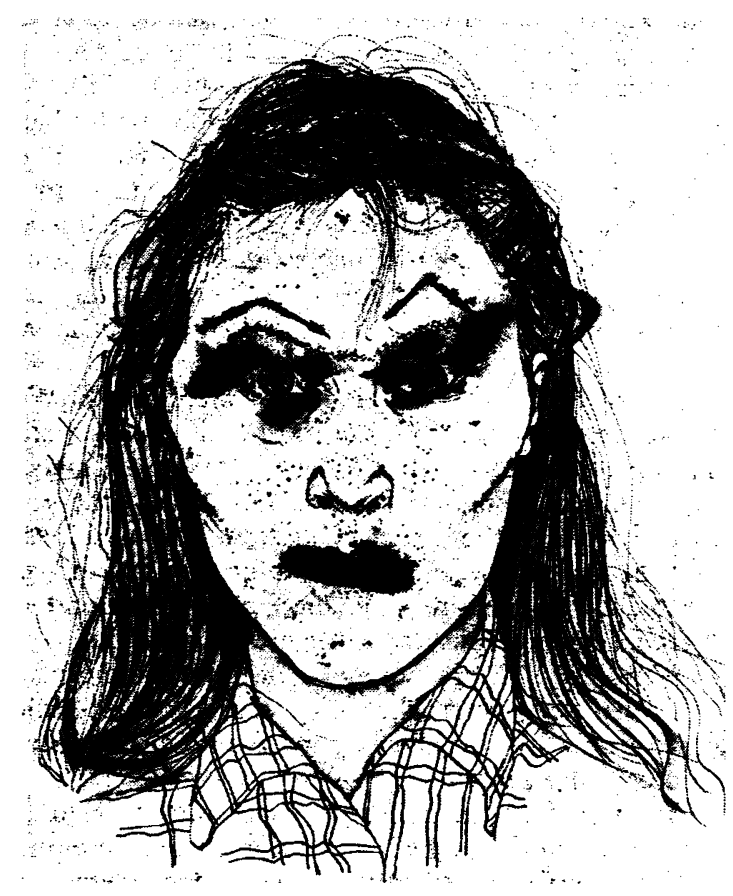

Does Friedreich's ataxia deteriorate more rapidly after pregnancy or does the physical strain of a child quickly magnify the underlying abnormalities? The clinical sign of bizarre facial make up is unreported, but we suspect that the absence of facial make up is much more common in patients with the condition.-K ANDERSON, W F DURWARD, Institute of Neurological Sciences, Southern General Hospital and Royal Infirmary, Glasgow.

1 Friedreich N. Uber degenerative Atrophie der spinalen Hinterstrange. Virchow's Archiv für Pathologische Anatomie und Physiologie und für Klinische Medizin 1863;26:391-419. 